\title{
SOME SPECULATION ON SIMULATION AND INFORMATION SYSTEMS
}

\author{
Henry C. Lucas, Jr.
}

An information systems as a set of procedures which process data used to support decision making. Robert Anthony (1965) has suggested a taxonomy of decision types which provides information useful in thinking about systems. Strategic planning dècisions involve setting the objectives of the organization. Managerial control decisions deal with the task of determining that resources are employed to achieve the goals set in strategic planning. Operational control decisions deal with the day-today operations of the firm.

This framework stresses the fact that there are different information requirements for different types of decision problems. For example, for strategic planning one rarely needs information that is current up to the minute, where such information may be vital for operational control decisions.

Information systems may or may not involve computers. However, much of the literature in the information systems field concerns computer-based systems since these systems seem to create some unique problems not associated with manual information systems.

Historically simulation and information systems have been closely connected. In fact, one can argue that a simulation model is an information system. The purpose of this paper is to discuss the role of simulation with respect to information systems. There have been two main interactions between information systems and simulation: the use of simulation as an information system as shown in rable $I$, and vice versa.

For the purposes of this paper simulation will be defined broadly. A simulation occurs when some type of model is used to predict a future event or outcome. A narrow definition of simulation might include only studies that employed a simulation language or used empirical data to paxameterize a model. However, econometric models and other types. of models are used for predictive purposes and to simulate future events or to ask "what if" questions. Simulation here also refers to both descrete and continuous models as either may be appropriate in a given situation.

\section{Models of Computer Systems}

One important role of simulation has been in the design of computer systems. Simulation has been employed extensively in configuring computer systems themselves. Specific simulation models have been written by a number of researchers to examine how some component of a computer system will function, for example, the behavior of a disk drive and its connection to the central processing unit. Such a simulation model might be written in a simulation language or it might be an analytical mathematical model. The model (s) could be used to predict the behavior of the disk and to redesign the hardware or software. Models of computer systems have included queuing approaches, stochastic and deterministic models and trace driven models. At least two proprietary models for simulating computer systems exist; users of these packages specify a configuration and provide the parameters of applications to the simulation package. The model uses extensive factor libxaries of empirical data to predict system behavior.

What is the future of this type of simulation? Modeling hardware is becoming less important as its cost drops. The proliferation of minicomputers and microprocessors means that extensive computer power is available at multiple locations. A critical issue becomes how to select and manage network of computers rather than the components of an individual system (sèe White, 1978).

Models of Organizations.

Early simulation efforts were directed at understanding and predicting human behavior, for example see Feigenbaum and Feldman 1963. Models were constructed of individual decision makers, especially the clarkson model of the trust investment officer in the reference above. This research demonstrated the difficulty of predicting and modeling individual human activity. For further studies of this type see Dutton and Starbuck, 1971.

Some efforts have also focused on the simulation of organizational information flows and of organizations themselves. The purpose of such simulation exercises is not always clear. More success has resulted from the simulation of a group 
INFORMATION SYSTEMS ... Continued.

SIMULATION TO DESIGN INFORMATION SYSTEMS

Models of computer systems

Quèuing

Stochastic

Deterministic

Trace ariven

Proprietary models

Models of organizations

Human decision makers

organizational information flows

SIMUTAATION AS AN INFORMATION SYSTEM

Models

Operations Research

Planning

Econometric

Deterministic

Stochastic

Prototypes

SIMULATION IN RESEARCH AND TRAINING ABOUT INFORMATION SYSTEMS

Games

Structural models

organizational behavior

Individual decision making

Intra organizational behavior

organization information and decision

systems

SIMULATION AND INFORMATION SYSTEMS

Table I

of interacting individuals; for example, see The Behavioral Theory of the Firm by Cyert and March. Application of this work to design a specific informations systems, however, is difficult.

\section{SIMULATION AS A COMPONENT OF AN INEORMATION SYSTEM}

Simulation can be considered as one type of information system. Information is processed by a model to aid the decision maker either for a one shot decision or on a continuing basis.

Models

Many operations research models are predictive or simulation models. One may try several optimizing models to provide a range of possible (simulated) outcomes for decision makers.

A particularly fertile area for future modeling is planning. Oxganizations are becoming extremely concerned about the potential impact of today's decisions on the future. Econometric models are being used by firms to examine the industry sub-section to which they belong. The next step for the organization is to develop an econo- metric model of its own operations with a national economics model supplying exogenous variables. such as a sales indicator for the industry which is highly correlated with company sales.

Other planning models employ proprietary Ianguages which are more natural to the planner than a language like Fortran or Basic. Using these larguages the planner builds a model of the firm, ustr ally employing difference equations, supplies data and simulates the outcome of various policy alternatives.

Some models can be constructed of an individual's decision problem. A popular type of such model is risk analysis which provides the decision maker with a probability distribution of likely outcomes for a decision.

For a description of planning systems employing all of these various models and integrated by an elaborate computer based graphics system see Hamilton and Moses, 1974.

Finally a prototype represents a very useful type of simulation model. Given the costs of constructing complex computer based information systems why not use available technology to build a smaller prototype system for testing. The prototype will contain parts that simulate the larger system which is expected to follow. In a sense, the prototype becomes a simulation of the final system. See Lucas 19.78 for an example. The availability of powerful easy to use time sharing languages and inexpensive computers makes this an attractive type of simulation model.

\section{SIMULATION FOR RESEARCH AND TRAINING}

Researchers will continue to use simulation for a variety of purposes and studies. Games which are a type of simulation, can help the player understand information systems better. Though few current games stress information systems concept, one can expect to see such teaching tools developed in the future.

Structural models such as those of an economist can be constructed of organization phenomenon like implementation. Using these models for simulation should help in understanding information systems as they exist in the context of the organization.

Research involving the simulation of organizations including individual decision makers will continue. This type of study also will help develop single individuals, groups, and organizations and multiple organizations.

\section{SUMMARY}

This paper has presented a brief overview of how simulation can be expected to interact with the information systems field in the future. The close relationship between the two fields in the past will become even stronger in the coming years. Simulation is becoming less expensive as hardware costs decline favoring it as a technique over more labor intensive analytical approaches. A simulation model is an information syotems and, as in- 
formation systems become more sophisticated, simulation wili become a greater part of information systems designed to support decision making in organizations.

REFERENCES

Anthony, R: Planning and Control Systems: A Framework for Analysis, Division of Research, Graduate School of Business Administration, Harward University, Boston, 1965.

Dutton, J. and W. Starbuck, Computer simulation of Human Behavior, New York. Jókn Wiley \& Sons, 1971.

Feigenbaum, E. and J. Feldman, Computers and Thought, New York; McGraw Hill Book Co.., 1963.

Hamilton, W. F. and M.A: Moses "A Computer Based Corporate Planning System," Management

Science, Vol. 21, No. 2 October 1974, pp. 148-159.

Lucas, H.C.Jr. "Performance Evaluation and Monitoring" Computing Surveys, Vol: 3, No. 3 Sept. 1971, pp. 79-91;

Lucas, H.C. Jr."The Evolution of An Information System: From Keyman to Every Person" Sloan Management Review (Winter, 1978), Vol. 19, No. 2, pp. 39-52;

White, N.H. "Simulating The Behavioral Implications of National Computer Résearch Network" New York Graduate School of Business Administration, N:Y.U. Working Paper \#78-48 May 1978. 